\title{
ДОСУДЕБНОЕ СОГЛАШЕНИЕ О СОТРУДНИЧЕСТВЕ: СОСТОЯНИЕ, ПРОБЛЕМЫ И ПЕРСПЕКТИВЫ
}

Аннотация: Авторы данной статьи подробно рассматривают вопросы досудебного соглашения о сотрудничестве. Представлен краткий анализ проблемных вопросов правовой регламентации данного института, который появился как необходимость противодействия групповым формам преступной деятельности, обладающей высокой латентностью и круговой порукой ее участников. Идея сделок, заключаемых между сторонами обвинения и защиты при производстве в суде первой инстанции, представляется достаточно перспективной, так как способствует упрощению и удешевлению порядка судебного разбирательства, отражает задачи предварительного расследования по установлению всех обстоятельств преступного события с одновременным повышением эффективности противодействия преступной деятельности в изелом. Методология исследования основана на анализе нормативных, доктринальных и эмпирических положениях. Материаль следственной и прокурорской практики свидетельствуют, что привлекаемые к сотрудничеству подозреваемые и обвиняемые являются соучастниками групповых преступлений с квалифицирующими признаками: «группа лиц», "группа лиц по предварительному сговору», «организованная группа». Основными выводами исследования являются: в главе 40.1 УПК РФ не содержится положений по особенностям защиты прав потерпевщего при заключении с подозреваемым (обвиняемым) досудебного соглашения о сотрудничестве. Учитывая правовые последствия составления соглашения (уменьшение размера наказания), предлагается предусмотреть три обязательных условия: 1) согласие потерпевиих, что требует изменения закона; 2) выполнение всех обязательств соглашения; 3) полное возмещение причиненного ущерба потерпевщему.

Ключевые слова: Досудебное соглашение, суд, ходатайство, потерпевиий, обвиняемый, подозреваемый, прокурор, ответственность, наказание, приговор.

Abstract: This article gives a detailed examination to the issues of pre-trial agreement to cooperate. The authors present a brief analysis of the problematic issues of the legal regulation of this institution that emerged as a necessity for counteracting organized forms of crime, which has high latency and loyalty among its members. The idea of deals, made between the defense and the prosecution during the first stages of judicial process, is rather promising, as it simplifies and eases the process of the court proceedings, and reflects the tasks of preliminary investigation on establishing all circumstances of the criminal act with simultaneous increase in efficiency of counteraction of the criminal activity as a whole. The materials of the investigative and prosecutorial practice confirmed that the cooperating suspects and defendants are in fact parties to organized crimes with the following qualifications: "group of people", "group of people based on conspiracy", "organized group". The authors make the conclusion that the Chapter 40.1 of the Criminal Procedural Code of the Russian Federation does not contain the positions on the specificity of protection of the rights of the victim in cases of cooperation with a suspect (defendant) of the pre-trial cooperation agreement.

Keywords: Responsibility, prosecutor, suspect, accused, victim, petition, court, pre-trial agreement, punishment, sentence.

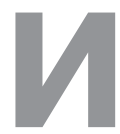

нститут досудебного соглашения о сотрудничестве с подозреваемым (обвиняемым) появился в отечественном уголовном и уголовно-процессуальном законодательстве в связи с принятием Федерального закона от 29 июня 2009 г. №141-Ф3 «О внесении изменений в Уголовный кодекс Российской Федерации и Уголовно-процессуальный кодекс Российской Федерации» [1, с. $17 ; 2 ; 3]$. Основным назначением института досудебного соглашения о сотрудничестве является необходимость противодействия групповым фор- мам «преступной деятельности, обладающей высокой латентностью и круговой порукой ее участников». Государство в лице законодателя, стремясь эффективно противодействовать этому негативному социальному феномену, вводит в УПК РФ компромиссный способ рассмотрения и разрешения уголовного дела.

Большинство криминалистов высказываются в поддержку рассматриваемого процессуального института, выражающего гуманистические идеи процессуальной экономии и углубляющие диспозитивное начало в отечественном уголовном про- 
цессе. Однако она подверглась и конструктивной критике [4, с. 3-11; 5, с. 90-95].

Вопросы правовой регламентации института досудебного соглашения о сотрудничестве нашли свое отражение в Постановлении Пленума Верховного Суда РФ от 28 июня 2012 г №16 «О практике применения судами особого порядка судебного разбирательства уголовных дел при заключении досудебного соглашения о сотрудничестве» [6, с. 2-5], а также в Постановлении Пленума Верховного Суда РФ от 22 декабря 2015 г. № 58 «О практике назначения судами Российской Федерации уголовного наказания» [7]. Сама идея сделок, заключаемых между сторонами обвинения и защиты при производстве в суде первой инстанции, видится достаточно перспективно. Сравнительный анализ содержания главы 40 УПК РФ и главы 40.1 УПК РФ свидетельствует о наличии много схожего, так как упрощают и ускоряют процедуру судопроизводства. Однако между ними есть и отличия [8, с. 69-73; 9, с.127-135; 10, с. 36-37].

Согласно главы 40 УПК РФ обвиняемый вправе ходатайствовать о постановлении приговора без проведения судебного разбирательства по уголовным делам о преступлениях, наказание за которые не превышает 10 лет лишения свободы (ст. 314 УПК РФ). В соответствии с главой 40.1 УПК РФ ограничение по максимальному наказанию для заявления ходатайства иные, оно может быть заявлено и по особо тяжким преступлениям.

Обвиняемый на основании ч. 2 ст. 315 УПК РФ вправе заявить ходатайство о рассмотрении его дела в порядке гл. 40 УПК РФ: 1) в момент ознакомления с материалами уголовного дела; 2) на предварительном слушании, когда оно является обязательным. Согласно ч.2 ст. 317.1 УПК РФ, подозреваемый или обвиняемый вправе заявить ходатайство о заключении досудебного соглашения о сотрудничестве с момента начала уголовного преследования до объявления об окончании предварительного следствия.

Таким образом, о предусмотренных в названных статьях ходатайствах в порядке гл. 40.1 УПК РФ, вправе заявить как обвиняемый, так и подозреваемый. Ходатайство в порядке главы 40 УПК РФ вправе заявить только обвиняемый.

Самое главное отличие для подсудимых - это размер максимального наказания. В соответствии со ст. 62 УК РФ, в случае заключения досудебного соглашения о сотрудничестве при наличии смягчающих обстоятельств, предусмотренных п. «и» ч. 1 ст. 61 УК РФ, и отсутствии отягчающих обстоятельств срок или размер наказания не могут превышать половину максимального срока или размера наиболее строго вида наказания, предусмотренного соответствующей статьей Особенной части УК РФ. В случае заключения досудебного соглашения о сотрудничестве, если соответствующая статья УК РФ предусматривает пожизненное лишение свободы или смертную казнь, то эти виды наказания не применяются. При этом срок или размер наказания не могут превышать двух третей максимального срока или размера наиболее строгого вида наказания в виде лишения свободы, предусмотренного соответствующей статьей Особенной части УК РФ.

При рассмотрении уголовного дела в порядке главы 40 УК РФ наказание подсудимому не может превышать две трети максимального срока или размера наиболее строгого вида наказания, предусмотренного за совершенное преступление (ч. 7 ст. 316 УПК РФ). Таким образом, гл. 40.1 УПК РФ на первый взгляд предусматривает гарантированное улучшение условий для назначения наказания лицам, совершившим преступления.

Досудебное соглашение (гл. 40 УПК РФ) в ч. 2 ст. 317.1 УПК РФ в сочетании с особым порядком применяет условия, при которых возможно соглашение: 1) подозреваемый или обвиняемый обязуется совершить конкретное действие в целях содействия следствию в раскрытии и расследовании преступлений, изобличению других соучастников преступления; 2) розыске имущества, добытого преступным путем. Следовательно, для того, чтобы дело было рассмотрено в порядке главы 40.1 УПК РФ, обвиняемый должен предпринять активные действия и сообщить сведения о совершенном преступлении. Для применения правил главы 40 УПК РФ достаточно (ч.1 ст. 314 УПК РФ), согласия обвиняемого с предъявленным ему обвинением $[11$, с. $81-85 ; 12$, с. 73-75].

При ознакомлении с содержанием этого процессуального института возникает вопрос: распространяются ли правила главы 40.1 УПК РФ на лиц, совершивших преступление в одиночку, или они распространяются только на лиц, совершивших групповые преступления? Материалы следственной практики показали, что, как правило, привлекаемые к сотрудничеству подозреваемые и обвиняемые являются соучастниками групповых преступлений, ответственность за совершение которых предусмотрена составами с квалифицирующими признаками: «группа лиц», «группа лиц по предварительному сговору», «организованная группа». 
Интересен тот факт, что в проанализированных материалах досудебного сотрудничества практически отсутствуют сведения об оказанном подозреваемым (обвиняемым) содействии в установлении похищенного имущества. Учитывая, что положение главы 40.1 УПК РФ не применяются, если содействие подозреваемого или обвиняемого следствию заключалось лишь в сообщении сведений о его собственном участии в преступной деятельности, то получается, что в большинстве случаев деятельность сотрудничающих лиц связана с выявлением соучастников преступлений $[13$, с. $105-111 ; 14 ; 15$, с. 21-27]. На наш взгляд, данное положение подтверждает, достижение цели введения института досудебного соглашения для борьбы с организованной преступностью.

Лица, ранее судимые за совершение умышленного преступления (за некоторыми исключениями), не вправе заключать досудебные соглашения о сотрудничестве. Насколько данное ограничение соответствует целям, указанным законодателем при введении главы 40.1 УПК РФ, вопрос спорный. Отметим, что в главе 40 УПК РФ нет ограничения на применение особого порядка при наличии рецидива преступлений и других отягчающих обстоятельств. Таким образом, для лиц, имеющих судимость, более предпочтительным остается рассмотрение их дела в порядке главы 40 УПК РФ, для этого им стоит только согласиться с предъявленным обвинением и заявить соответствующее ходатайство.

Анализ содержания п.П. 46, 47, 61 ст. 5 УПК РФ и главы 40.1 УПК РФ, показывает, что сторонами соглашения выступают только прокурор и обвиняемый, которые подписывают соглашение. Другие участники со стороны обвинения и защиты являются лишь участниками уголовно-процессуальных отношений, возникающих в связи с заключением или исполнением досудебного соглашения о сотрудничестве. К сожалению, ни одна статья главы 40.1 УПК РФ не содержит положений по особенностям защиты прав потерпевшего при заключении с подозреваемым (обвиняемым) досудебного соглашения о сотрудничестве. Следовательно, они реализуются по общим правилам (на сегодняшний день в обеспечении прав множество проблем) [16, с. $35-36 ; 17$, с. $5-14]$.

На наш взгляд, учитывая правовые последствия составления соглашения (уменьшение размера наказания), целесообразно предусмотреть три обязательных условия: 1) согласие потерпевших, что требует изменения закона; 2) выполнение всех обязательств соглашения; 3) полное возмещение причиненного ущерба потерпевшему. Безусловно, оптимальным способом защиты имущественных прав потерпевшего является добровольное возмещение подозреваемым, обвиняемым вреда, причиненного преступлением. Мы поддерживаем мнение Я.В. Лошкобановой, что для создания надлежащей мотивации подозреваемого, обвиняемого к добровольному возмещению имущественного вреда, целесообразно дополнить ч. 1 ст. 317 УПК РФ пунктом 5 следующего содержания: «5) наличие возмещения имущественного и (или) морального вреда, причинённых в результате преступления, а также иные действия, направленные на заглаживание вреда, причинённого потерпевшему» [18, с. 23].

Прокурор не назван в число должностных лиц, уполномоченных рассматривать жалобу подозреваемого, обвиняемого на решение следователя. Полагаем, что такое законодательное решение необоснованно ущемляет права участников уголовного процесса, ограничивает возможность защиты их прав и противоречит правовому статусу прокурора как должностного лица со стороны обвинения, уполномоченного принимать решения о заключении досудебного соглашения о сотрудничестве. Кроме того, сегодня выделение дела в отношении заключавшего соглашение лица будет производиться следователем во всех случаях. Однако при таком подходе нерешенными остаются проблемы при раздельном рассмотрении дел в отношении соучастников преступления [19, с. 98-102; 20, с. 21-24].

Следует исключить из нормы закона входящих в главу 40.1 УПК РФ упоминание о «раскрытии преступления», сохранив «расследование преступления». Данное суждение основано на том, что в нормах уголовно-процессуального кодекса РФ и в официальных опубликованиях подзаконных актах содержание понятия «раскрытие преступления» не определенно.

В теории уголовного процесса также не сложилось единого мнения о том, на каком этапе производства по уголовному делу и при каких (условных, можно было бы считать то или иное преступление «раскрытым»). В связи с этим любые ссылки на «раскрытие преступления», юридически несостоятельны и беспредметны. Не имея юридического значения, подобные ссылки не могут повлечь за собой правовые последствия и, следовательно, не смогут быть правовым или фактическим условием заключения досудебного соглашения о сотрудничестве путем выдвижения 
максимально жесткого обвинения [21, с. 22-24; 22 , с. $92-93]$.

Заключение с подозреваемым (обвиняемым) досудебного соглашения о сотрудничестве предполагает наличие ряда условий, изложенных в уголовном и уголовно-процессуальном законодательстве. Вполне очевидно и оправдано, что подобный компромиссный способ разрешения уголовно-правовых споров применим не по всем уголовным делам. В противном случае представляется возможным утрата императивной составляющей в уголовном законодательстве и подрыв его превентивных функций. В отличие от положения главы 40 УПК РФ в главе 40.1 УПК РФ не указаны категория преступлений, по делам о которых возможно ее применение, степень тяжести, конкретные составы, круг субъектов. Это приводит к тому, что в уголовно-правовой литературе ведутся споры о том, можно ли изменить категорию преступления при особом порядке принятия судебного решения в соответствии с главами 40 и 40.1 УПК РФ [23, с. $42-45 ; 24$, с. $57-64 ; 25$, с. $39-40]$.

Институт досудебного соглашения о сотрудничестве характеризуется свойством комплексности - положения о нем содержаться как в уголовном, так и уголовно-процессуальном законодательстве. Условия (основания) заключения досудебного соглашения о сотрудничестве следует подразделить на две группы: уголовно-правовые и уголовно-процессуальные. При этом необходимо отметить, что уголовно-правовые условия выступают в качестве основной для заключения досудебного соглашения о сотрудничестве на стадии предварительного расследования, а уголовно-процессуальные условия - основания для применения особого порядка проведения судебного заседания и вынесения судебного решения [26, с. 17], например, отсутствие такого этапа как судебное следствие

Нами в дальнейшем рассматриваются условия ответственности лица, заключившего досудебное соглашение, которое в основном определяются уголовно-правовыми положениями ч. 2 и 4 ст. 62 УК РФ. Исходя из разных законодательных положений возможно выделение двух подгрупп уголовно-правовых условий: 1) наличие смягчающих обстоятельств, предусмотренных п. «и» ч. 1 ст. 61 УК РФ. К таковому относится следующие: явка с повинной [27, с. 30-32; 28, с. 142-151], активнее способствовали раскрытию и расследованию преступления, изобличению и уголовному рассмотрению других соучастников преступления, розыску имущества, добытого в результате преступления;
2) отсутствие отягчающих обстоятельств, предусмотренных ст. 63 УК РФ.

Возникает ряд вопросов, решение которых существенным образом сказывается на совершенствовании особого порядка принятия решения при наличии досудебного соглашения о сотрудничестве. Так, остается неясным, требуется ли по смыслу закона для заключения соглашения наличия всех смягчающих обстоятельств, предусматривающих в п. «и» ч. 1 ст. 61 УК РФ? Например, обязательно ли наличие явки с повинной при заключении досудебного соглашения о сотрудничестве? Из буквального толкования положений ст. 62 УК РФ следует, что отсутствие хотя бы одного из обстоятельств, перечисленных в п. «и» ч. 1 ст. 61 УК РФ, независимо от последующего посткриминального поведения лица, делает невозможным применение к нему благоприятных последствий, указанных в ч. 2 ст. 62 УК РФ. Можно, конечно, истолковать указанную формулировку ограничительно, как не требующую наличия всех вышеуказанных элементов посткриминального поведения [29, c. 21-26].

Сложнее с пониманием требований об отсутствии отягчающих обстоятельств как условия заключения досудебного соглашения. Это требование вступает в противоречие с положением, содержащимся в ч.2 ст. 317 УПК РФ, согласно которому предметом досудебного соглашения могут быть действия по изобличению и уголовному преследованию других соучастников преступления. Дело в том, что совершение преступления в составе группы лиц по предварительному сговору, организованной группой или преступного сообщества (преступной организации) являются обстоятельствами, отягчающими наказание (п. «в» ч. 1 ст. 61 УК РФ). Если уголовный закон понимать буквально, то заключение досудебного соглашения в указанных случаях невозможно. Полагаем, что судебная практика пойдет по пути игнорирования этого обстоятельства, исходя из потребности раскрытия и расследования преступлений, совершенных в соучастии. Однако это не решает проблемы рассогласованности законов и реализация принципа законности [30, с. 118-123; 31, с. 76-79].

Остается вопрос о соучастниках преступной деятельности. Неясно, должны ли у подозреваемого или обвиняемого быть соучастники в совершении именного того преступления, по поводу которого заключено соглашение, или же он может оказывать содействие следствию по другим преступлениям 
иных лиц, чтобы добиться для себя права на применение особого порядка? Использование термина «преступная деятельность»не оставляет возможности применения данного института в тех случаях, когда лицо, уличенное в совершении одного преступления готово сотрудничать со следствием в расследовании и раскрытии других совершенных им преступлений, а без его содействия достичь задач правосудия не представляемые возможным. В то же время для применения п. «и»ч. 1 ст. 61 УК РФ и ч. 1 ст. 62 УК РФ достаточно способствования раскрытию и расследованию конкретного преступления, за совершение которого виновник привлекается к уголовной ответственности. Вряд ли это способствует повышению эффективности борьбы с преступностью и обеспечению принципа неотвратимости наказания [21, с. 22-24].

По нашему мнению, целесообразно заключать досудебное соглашение о сотрудничестве также с лицами, сообщающими сведения только о собственном участии в совершении преступления. Достаточно весомыми представляются аргументы, указывающие, что многие тяжкие и особо тяжкие серийные преступления, совершаются одним лицом, в таком случае они могут оставаться нераскрытыми. Кроме того, законом не разрешен вопрос о возможном количестве лиц, с которыми возможно заключение досудебного соглашения о сотрудничестве в рамках одного уголовного дела.

В настоящее время судебно-следственная и прокурорская практика ориентирована на вариант, когда в рамках одного уголовного дела возможно заключение досудебного соглашения о сотрудничестве сразу с несколькими подозреваемыми (обвиняемыми), если для этого имеются веские основания. При этом заключение досудебного соглашения о сотрудничестве с одним или несколькими из них является правом прокурора. Полагаем, что, совершенствование условий и оснований заключения досудебного соглашения о сотрудничестве предопределяет эффективное и качественное функционирование рассматриваемого института в целом.

\section{Библиография:}

1. Федеральный закон от 29 июня 2009 г. №141-Ф3 «О внесении изменений в Уголовный кодекс Российской Федерации и Уголовно-процессуальный кодекс Российской Федерации» // Собрание законодательства РФ, 2009, №26, Ст. 3139.

2. Уголовный кодекс Российской Федерации от 13.06.1996 № 63-Ф3 (ред. от 30.12.2015). - М.: Проспект, КноРус, 2015.

3. Уголовно-процессуальный кодекс Российской Федерации от 18.12. 2001 № 174-ФЗ (ред. от 02. 03.2016). - М.: Проспект, КноРус, 2016.

4. Александров А.С.. Александрова И.А. Соглашение о досудебном сотрудничестве со следствием: правовая сущность и вопросы толкования норм, входящих в главу 40.1 УПК РФ // Уголовный процесс, 2009, №8, С. 3-11.

5. Днепровская М., Степаненко Д. Досудебное соглашение о сотрудничестве // Уголовное право. - М.: АНО «Юридические программы», 2013, № 4. - С. 90-95.

6. Постановление Пленума Верховного Суда РФ от 28 июня 2012 г №16 «О практике применения судами особого порядка судебного разбирательства уголовных дел при заключении досудебного соглашения о сотрудничестве // Бюллетень Верховного Суда РФ, 2012, №9. С. 2-5.

7. Постановление Пленума Верховного Суда РФ от 22 декабря 2015 г. № 58 «О практике назначения судами Российской Федерации уголовного наказания» http://base.consultant.ru/cons/cgi/online.cgi?req=doc;base=LAW;n=190932;fld=134;ds $\mathrm{t}=1000000001,0 ; \mathrm{rnd}=0.5017763487749336$

8. Манова Н.С. Упрощённые судебные процедуры и сделки о признании вины // Закон, 2009. №1, С. 69-73.

9. Головко Л.В. Институт уголовно-правовой медиации и его перспективы в Российской Федерации // Закон, 2009, №4, C. $127-135$

10. Гуршумов И. Досудебное соглашение о сотрудничестве - сделка с правосудием? // Законность, 2010, №4. С. 36-37.

11. Гричаниченко А. Особый порядок принятия судебного решения: сравнительный анализ содержания главы 40 и 40.1 УПК РФ, проблемы их применения // Уголовное право, 2010, №1. С. 81-85.

12. Абщилава Г. Комбинаторика уголовно-процессуальных форм при реализации досудебного соглашения о сотрудничестве // Уголовное право, 2010, №3, С. 73-75.

13. Тимошенко А. Досудебное соглашение о сотрудничестве с оценкой эффективности процессуального института // Уголовное право, 2011, №4, С. 105-111.

14. Хомицкая Т.П. Комментарий к постановлению Пленума Верховного Суда Российской Федерации о применении судами норм главы 401 УПК РФ // Уголовный процесс. 2012. № 9. С. 76.

15. Досудебное соглашение о сотрудничестве. Проблемы совершенствования / Под ред. Ф.Ф. Зиннурова, Г.Б. Мирзоева. - М..: ЮНИТИ ДАНА: Закон и право, 2014, С. 21-27.

16. Чабукиани О.А. Гарантии прав потерпевших при заключении стороной обвинения досудебного соглашения о сотрудничестве с подозреваемым (обвиняемым) // Рос. юстиция, 2012, №4, С. 35-36.

17. Смирнов А.В. Особый порядок практики судебного решения, при заключении досудебного соглашения о сотрудничестве // Уголовный процесс, 2009, №10, С. 5-14. 
18. Лошкобанова Я.В. Обеспечение прав и законных интересов подозреваемого, обвиняемого и потерпевшего при заключении досудебного соглашения о сотрудничестве. Автореф. канд. юрид. наук. - Краснодар, 2015, С. 23.

19. Халиулин А., Буланова Н., Конярова Ж. Полномочия прокурора по заключению досудебного соглашения о сотрудничестве // Уголовное право, 2010, №3, С. 98-102.

20. 20. Новиков С.А. Досудебное соглашение о сотрудничестве как основание для выделения уголовного дела // Рос. судья, 2012, №11, с. 21-24.

21. Морозов В. Уголовно-правовое обеспечение института досудебного соглашения о сотрудничестве: проблемы и решения // Уголовное права, 2010, №1, С. 22-24.

22. Мешков М.В., Гончаров В.В. Досудебное соглашение о сотрудничестве: проблемы и перспективы // Закон и право, 2011, №1, С. 92-93.

23. Виницкий Л., Кубрикова М. Возможно ли изменение категории при рассмотрении уголовного дела в порядке главы 40.1 УПК РФ? // Законность, 2013, №3, С. 42-45.

24. Павлова Е.Ю. Основания и условия изменения категории преступления на менее тяжкую // Законодательство, 2014, №2, С. 57-64.

25. Иванов А. Рекомендации Пленума Верховного Суда РФ о применении ч.6 ст. 15 УК // Законность, 2014, №8. С. $39-40$.

26. Александров А.С., Кучин А.Ф., Смолин А.Г. Правовая природа института, регламентированного главой 40 УПК РФ // Рос. судья, 2007, №7, С. 17.

27. Журавлева Е. Явка с повинной в судебной практике, как обстоятельство, смягчающее наказание осужденного // Уголовное право, 2007, №5, С. 30-32.

28. Мачульская Е.А. Юридические аспекты явки с повинной // Журнал российского права, 2008, №9, С. 142-151.

29. Благов Е. Назначение наказания в случае заключения досудебного соглашения о сотрудничестве // Уголовное право, 2010, №3, С. 21-26.

30. Стовповой А.. Тюнин В. Уголовно-правовой и уголовно-процессуальный аспекты досудебного соглашения о сотрудничестве на предварительном следствии // Уголовное право, 2010, №3. С.118-123.

31. Гранкин К., Мильтова Е. Проблемы применения норм УПК РФ, регулирующих досудебное соглашение о сотрудничестве // Уголовное право, 2010, №3, С. 76-79.

32. Хамидуллин Р.С. Досудебное соглашение о сотрудничестве как тактико-криминалистический элемент борьбы с организованной преступностью // Союз криминалистов и криминологов. - 2014. - 3. - С. 250 - 255. DOI: 10.7256/23108681.2014.4.15610.

33. Хамидуллин Р.С. Некоторые особенности расследования уголовных дел в случае применения норм особого уголовного судопроизводства при заключении досудебного соглашения о сотрудничестве // Полицейская и следственная деятельность. - 2015. - 3. - С. 9 - 16. DOI: 10.7256/2409-7810.2015.3.15617. URL: http://www.e-notabene.ru/pm/article_15617.html

34. Хамидуллин Р.С. Досудебное соглашение о сотрудничестве- объективная истина или компромисс? // Юридические исследования. -2016. -3.-C. 16-22. DOI: 10.7256/2409-7136.2016.3.17925. URL: http://www.e-notabene.ru/lr/article_17925.html

\section{References (transliterated):}

1. Aleksandrov A.S.. Aleksandrova I.A. Soglashenie o dosudebnom sotrudnichestve so sledstviem: pravovaya sushchnost' i voprosy tolkovaniya norm, vkhodyashchikh v glavu 40.1 UPK RF // Ugolovnyi protsess, 2009, №8, S. 3-11.

2. Dneprovskaya M., Stepanenko D. Dosudebnoe soglashenie o sotrudnichestve // Ugolovnoe pravo. - M.: ANO "Yuridicheskie programmy", 2013, № 4. - S. 90-95.

3. Manova N.S. Uproshchennye sudebnye protsedury i sdelki o priznanii viny // Zakon, 2009. №1, S. 69-73.

4. Golovko L.V. Institut ugolovno-pravovoi mediatsii i ego perspektivy v Rossiiskoi Federatsii // Zakon, 2009, №4, S. 127-135.

5. Gurshumov I. Dosudebnoe soglashenie o sotrudnichestve - sdelka s pravosudiem? // Zakonnost', 2010, №4. S. 36-37.

6. Grichanichenko A. Osobyi poryadok prinyatiya sudebnogo resheniya: sravnitel'nyi analiz soderzhaniya glavy 40 i 40.1 UPK RF, problemy ikh primeneniya // Ugolovnoe pravo, 2010, №1. S. 81-85.

7. Abshchilava G. Kombinatorika ugolovno-protsessual'nykh form pri realizatsii dosudebnogo soglasheniya o sotrudnichestve // Ugolovnoe pravo, 2010, №3, S. 73-75.

8. Timoshenko A. Dosudebnoe soglashenie o sotrudnichestve s otsenkoi effektivnosti protsessual'nogo instituta // Ugolovnoe pravo, 2011, №4, S. 105-111.

9. Khomitskaya T.P. Kommentarii k postanovleniyu Plenuma Verkhovnogo Suda Rossiiskoi Federatsii o primenenii sudami norm glavy 401 UPK RF // Ugolovnyi protsess. 2012. № 9. S. 76.

10. Chabukiani O.A. Garantii prav poterpevshikh pri zaklyuchenii storonoi obvineniya dosudebnogo soglasheniya o sotrudnichestve s podozrevaemym (obvinyaemym) // Ros. yustitsiya, 2012, №4, S. 35-36.

11. Smirnov A.V. Osobyi poryadok praktiki sudebnogo resheniya, pri zaklyuchenii dosudebnogo soglasheniya o sotrudnichestve // Ugolovnyi protsess, 2009, №10, S. 5-14.

12. Loshkobanova Ya.V. Obespechenie prav i zakonnykh interesov podozrevaemogo, obvinyaemogo i poterpevshego pri zaklyuchenii dosudebnogo soglasheniya o sotrudnichestve. Avtoref. kand. yurid. nauk. - Krasnodar, 2015, S. 23.

13. Khaliulin A., Bulanova N., Konyarova Zh. Polnomochiya prokurora po zaklyucheniyu dosudebnogo soglasheniya o sotrudnichestve // Ugolovnoe pravo, 2010, №3, S. 98-102.

14. Novikov S.A. Dosudebnoe soglashenie o sotrudnichestve kak osnovanie dlya vydeleniya ugolovnogo dela // Ros. sud'ya, 2012, №11, s. 21-24. 
DOI: $10.7256 / 1811-9018.2016 .5 .18561$

При цитировании этой статьи сноска на dоі обязательна

Право и политика $5(197) \cdot 2016$

15. Morozov V. Ugolovno-pravovoe obespechenie instituta dosudebnogo soglasheniya o sotrudnichestve: problemy i resheniya // Ugolovnoe prava, 2010, №1, S. 22-24.

16. Meshkov M.V., Goncharov V.V. Dosudebnoe soglashenie o sotrudnichestve: problemy i perspektivy // Zakon i pravo, 2011, №1, S. 92-93.

17. Vinitskii L., Kubrikova M. Vozmozhno li izmenenie kategorii pri rassmotrenii ugolovnogo dela v poryadke glavy 40.1 UPK RF? // Zakonnost', 2013, №3, S. 42-45.

18. Pavlova E.Yu. Osnovaniya i usloviya izmeneniya kategorii prestupleniya na menee tyazhkuyu // Zakonodatel'stvo, 2014, №2, S. 57-64.

19. Ivanov A. Rekomendatsii Plenuma Verkhovnogo Suda RF o primenenii ch.6 st. 15 UK // Zakonnost', 2014, №8. S. 39-40.

20. Aleksandrov A.S., Kuchin A.F., Smolin A.G. Pravovaya priroda instituta, reglamentirovannogo glavoi 40 UPK RF // Ros. sud'ya, 2007, №7, S. 17.

21. Zhuravleva E. Yavka s povinnoi v sudebnoi praktike, kak obstoyatel'stvo, smyagchayushchee nakazanie osuzhdennogo // Ugolovnoe pravo, 2007, №5, S. 30-32.

22. Machul'skaya E.A. Yuridicheskie aspekty yavki s povinnoi // Zhurnal rossiiskogo prava, 2008, №9, S. 142-151.

23. Blagov E. Naznachenie nakazaniya v sluchae zaklyucheniya dosudebnogo soglasheniya o sotrudnichestve // Ugolovnoe pravo, 2010, №3, S. 21-26.

24. Stovpovoi A.. Tyunin V. Ugolovno-pravovoi i ugolovno-protsessual'nyi aspekty dosudebnogo soglasheniya o sotrudnichestve na predvaritel’nom sledstvii // Ugolovnoe pravo, 2010, №3. S.118-123.

25. Grankin K., Mil'tova E. Problemy primeneniya norm UPK RF, reguliruyushchikh dosudebnoe soglashenie o sotrudnichestve // Ugolovnoe pravo, 2010, №3, S. 76-79.

26. Khamidullin R.S. Dosudebnoe soglashenie o sotrudnichestve kak taktiko-kriminalisticheskii element bor'by s organizovannoi prestupnost'yu // Soyuz kriminalistov i kriminologov. - 2014. - 3. - C. 250 - 255. DOI: 10.7256/2310-8681.2014.4.15610.

27. Khamidullin R.S. Nekotorye osobennosti rassledovaniya ugolovnykh del v sluchae primeneniya norm osobogo ugolovnogo sudoproizvodstva pri zaklyuchenii dosudebnogo soglasheniya o sotrudnichestve // Politseiskaya i sledstvennaya deyatel'nost'. - 2015. - 3. - C. 9 - 16. DOI: 10.7256/2409-7810.2015.3.15617. URL: http://www.e-notabene.ru/pm/article_15617.html

28. Khamidullin R.S. Dosudebnoe soglashenie o sotrudnichestve - ob"ektivnaya istina ili kompromiss? // Yuridicheskie issledovaniya. - 2016. - 3. - C. 16-22. DOI: 10.7256/2409-7136.2016.3.17925. URL: http://www.e-notabene.ru/lr/article 17925.html 